\title{
MEMBANGUN SUMBER DAYA MANUSIA BERKELANJUTAN PADA KOMUNITAS ADAT TERPENCIL (STUDI KASUS SUKU ANAK DALAM DI TAMAN NASIONAL BUKIT DUABELAS JAMBI)
}

\author{
Rina Astarika ${ }^{1)}$ Partini Endang ${ }^{2)}$ Sulastri $^{3)}$ \\ Email: ${ }^{1)}$ rinaastarika@gmail.com
}

\begin{abstract}
ABSTRAK
Moderenisasi dan Globalisasi mengancam keberlanjutan kehidupan Komunitas Adat Terpencil (KAT) di Indonesia, khususnya Suku Anak Dalam (SAD) yang mendiami hutan belantara Sumatera. Karakter SAD yang terpencar dan belum terlibat dalam berbagai jaringan dan pelayanan sosial,ekonomi, politik, membuat komunitas ini semakin termarginalkan. Pendidikan merupakan salah satu solusi untuk mengubah keadaan ini. Penelitian ini bertujuan untuk mengetahui model pendidikan seperti apa yang dibutuhkan SAD dan mengetahui pemberdayaan apa saja yang sudah dilakukan untuk mereka. Penelitian dilakukan di Desa Bukit Suban Kecamatan Air Hitam Kabupaten Sarolangun. Data penelitian dianalisis dengan menggunakan model studi kasus. Hasil penelitian menunjukkan bahwa Model pembedayaan pendidikan alternatif yang berdasarkan pada aspek Kultural budaya setempat, yang mudah diterima oleh SAD. Pemerintah, Swasta dan LSM terlibat aktif dalam pemberdayaan pendidikan bagi SAD. Swasta dan LSM bergerak di pendidikan alternatif yang bersifat non formal, sedangkan Pemerintah memberikan pelayanan pendidikan formal dan juga non formal. Pendidikan membawa perubahan cara pandang, pendidikan bagi SAD merupakan simbol perlawanan dari penindasan.
\end{abstract}

Kata Kunci: Pendidikan, Suku Anak Dalam (SAD), Perubahan

\section{PENDAHULUAN}

Suku Anak Dalam (SAD) merupakan salah satu dari 2349 Komunitas Adat Terpencil (KAT) yang ada di Indonesia. Komunitas Adat Terpencil atau disingkat KAT adalah kelompok sosial budaya yang bersifat lokal dan hidup terpencar serta kurang atau belum terlibat dalam jaringan dan pelayanan baik sosial, ekonomi, maupun politik. SAD adalah 
kelompok suku bangsa yang mendiami hutan di Jambi, Sumatera. SAD digolongkan sebagai suku bangsa minoritas (Suparlan, 2004). Keminoritasan suatu kelompok tidak selalu berkaitan dengan jumlah populasi atau keanggotaan suatu kelompok, tetapi lebih pada status marginal yang dipunyai kelompok tersebut terhadap kelompok lain yang dianggap lebih dominan ( Seymour, 1987). Sebagai suku bangsa minoritas, SAD diperlakukan berbeda dengan suku lainnya. Masyarakat Jambi mengenal SAD dengan sebutan suku Kubu yang identik dengan kebodohan, kemiskinan dan keterbelakangan (Prasetijo, 2011)

Tingginya arus modernisasi dan globalisasi pada dua dekade terakhir berimplikasi kepada sustainable Suku Anak Dalam (SAD). Arus modernisasi tersebut menjadi sebuah ancaman bagi SAD, baik dari segi ekonomi, sosial politik dan kebudayaan. Untuk mampu mempertahankan keberlangsungan hidupnya, SAD harus menyikapi modernisasi ini dengan bijak dan menggunakan segala pengetahuan yang mereka miliki. Dengan begitu, mereka mampu untuk tetap hidup dan bertahan di dunia modern seperti sekarang.

Pengetahuan yang dimiliki SAD, adalah pengetahuan lisan yang bersumber dari norma dan adat yang berlaku serta petatah petitih tetua adat. Awalnya dengan pengetahuan yang di miliki, SAD sudah tinggal dengan tenang di dalam hutan. Akan tetapi ketika praktekpraktek pembangunan giat dilancarkan mulai tahun 1970-an, membuat kehancuran hutan hujan tropis di wilayah Bukit Duabelas Jambi. Eksploitasi sumber daya alam besar besaran dilakukan demi mendorong pertumbuhan ekonomi, menyebabkan hutan di Jambi mendapatkan tekanan yang siginifikan (Rokhdian, 2012).

Dipicu oleh kerusakan hutan, maka kehidupan SAD pun berubah. Semakin sempit hutan berarti semakin sempit luas jelajah dari SAD yang menyebabkan mereka kesulitan mencari sumber makanan dan kebutuhan. Selain itu keterbukaan akses dengan dunia luar menimbulkan efek negatif bagi SAD. Posisi SAD yang kurang mendapatkan pendidikan semakin menyulitkan mereka jika dihadapkan dengan keterbukaan akses. Ketidaktahuan mereka dengan angka dan huruf menyebabkan mereka sering ditipu oleh pihak luar. Seringkali SAD ditipu oleh oknum tertentu yang menunjukkan sepucuk surat perintah, karena SAD tidak mampu membaca maka mereka hanya mengikuti apa yang diperintah oknum tersebut. Kerap kali surat tersebut membawa kerugian bagi masyarakat SAD. Pengusiran dan penipuan dalam hal perdagangan seringkali SAD alami. Melihat kondisi ini, SAD mulai menyadari arti pentingnya pendidikan (Manan, 2018)

Pendidikan bagi KAT dijamin dalam UU No 20 Tahun 2003 tentang Sistem Pendidikan Nasional. Pasal 5 ayat 3 menyatakan bahwa “ Warga Negara di daerah terpencil 
atau terbelakang serta masyarakat adat terpencil berhak memperoleh pendidikan layanan khusus." Pasal diatas memberikan gambaran kepada kita semua bahwa dari segi hak, jaminan bagi masyarakat adat untuk memperoleh layanan pendidikan dari Negara sudah cukup jelas. Artinya undang-undang menjamin hak hak mereka secara jelas. Negara memiliki kewajiban untuk memenuhinya, karena mencerdaskan kehidupan bangsa merupakan salah satu tugas Negara yang diamanatkan oleh konstitusi ( Apriansyah, 2015).

Masih banyak masyarakat SAD yang belum mendapatkan pendidikan, baik itu pendidikan non formal maupun formal. Pendidikan yang layak, sesuai dengan adat dan budaya setempat tentu merupakan harapan semua pihak Hanya saja meski sudah 73 Tahun Indonesia merdeka, pendidikan yang layak dan merata masih belum dirasakan sebagian warga negara, terutama masyarakat adat (SAD) yang hidup dalam kondisi marginal dan terpinggirkan. Dari satu aspek yaitu pendidikan saja (SAD) belum mendapatkan keadilan yang merata. Jika melihat fenomena di atas, maka dirasa perlu untuk melakukan penelitian ini. Pedidikan seperti apa yang dibutuhkan SAD untuk menunjang kehidupan modern, apa saja upaya yang sudah dilakukan "Aktor Pemberdaya" (Pemerintah, Swasta, LSM) untuk meningkatkan dan mengembangkan kualitas SDM SAD merupakan tujuan utama dalam penelitian ini.

\section{METODE PENELITIAN}

Penelitian dilakukan di Desa Bukit Suban Kecamatan Air Hitam Kabupaten Sarolangun Propinsi Jambi, yaitu pada rombong Suku Anak Dalam yang telah menetap. Lokasi penelitian ditentukan dengan sengaja (purposive), karena didaerah ini merupakan kawasan terpadu dalam memberdayakan SAD. Penelitian dilakukan selama satu bulan, dimulai Februari sampai Maret 2018. Data yang diperlukan dalam penelitian adalah data primer dan data sekunder. Pengumpulan data menggunakan tekhnik bola salju ( snowball). Secara spesifik penelitian ini menggunakan metode studi kasus.

\section{HASIL DAN PEMBAHASAN}

\subsection{Arti Pengetahuan Bagi Suku Anak Dalam}

"Education is the last War"

Pendidikan adalah perang terakhir bagi bangsa untuk tetap berjati diri dan bermartabat. Arus Globalisasi yang begitu deras telah menjadikan pendidikan sebagai salah satu mediumnya, pendidikan nasional Indonesia bahkan mulai lupa bahwa budaya bangsa seharusnya menjadi common interest bagi dunia pendidikan. Ketika orang Indonesia jauh 
lebih bangga dengan nilai dan budaya dari luar dibandingkan dari dalam negeri sendiri, menandakan ada yang tidak beres dalam pendidikan kita. (Apriansyah, 2014).

Sebelum hadirnya pendidikan, masyarakat Suku Anak Dalam (SAD) mempelajari pengetahuan dengan menggunakan sistem sekola pada indok bepak. Sistem ini merupakan sebuah sistem pengasuhan anak oleh orang tuanya. Secara harfiah sekola pada indok bepak berarti sekolah pada ibu dan bapak (orang tua). Proses ini merupakan pendidikan tradisional yang diberikan oleh orang tua kepada anak-anak SAD. Segala sesuatu yang sangat erat dengan kehidupan SAD wajib diajarkan kepada anak-anak agar nantinya anak-anak mampu hidup mandiri ( Manan, 2018).

Berbagai pengetahuan diberikan kepada anak anak mereka. Memasuki umur 5 tahun, sudah ada pembedaan materi ajar antara perempuan dan laki-laki. Untuk perempuan, mereka diajarkan mengenai aktivitas perempuan SAD seperti kegiatan domistik dan kerajinan tangan. Anak laki-laki mulai diajarkan untuk memimpin dan bertanggung jawab. Selain itu, anak laki-laki wajib membantu orang tua mereka untuk memenuhi kebutuhan hidup keluarga. Dari mulai berburu, meramu hingga bercocok tanam harus dapat dimengerti oleh sang anak. Pengalaman yang didapat selama membantu orang tua berburu, meramu dan bercocok tanam itulah yang menjadi bahan ajar agar mampu menjalani kehidupan di masa mendatang.

Menginjak dewasa atau pada usia remaja mereka juga diikutsertakan pada setiap proses adat dan forum adat. Pengajaran adat dilakukan oleh orang tua, dan para pemegang jabatan dalam suatu kelompok seperti Temenggung, Depati, Mangku atau rerayo. Kegiatan ini menjadi sebuah proses pengenalan adat dan budaya Suku Anak Dalam kepada generasi berikutnya. Puluhan bahkan ratusan tahun SAD menikmati pola pengetahuan sepertini ini. Dengan pengetahuan yang didapat dari Indok bepak, para rerayo dan Tetua adat mereka belajar menjaga hubungan yang baik dengan hutannya. Alam hutan (Halom Rimba) adalah nadi kehidupan SAD yang harus mereka jaga dan rawat dengan baik. Namun sayangnya nadi kehidupan ini banyak dirusak oleh pihak pihak yang memiliki banyak kepentingan. HPH (Hak Penguasaan Hutan), HTI (Hutan Tanaman Industri), Transmigrasi, illegal logging yang berdampak pada kerusakan Halom Rimba. 


\subsection{Model Pendidikan Suku Anak Dalam}

Ditengah kehidupan saat ini, rusaknya Halom Rimba dan moderenisasi melanda kehidupan SAD, maka model pendidikan yang mereka butuhkan adalah yang menekankan pada aspek budaya lokal, karakter geografis,ekonomi, sosial, ekonomi setempat, sebab terlalu naïf bila pendidikan SAD ini tunduk sepenuhnya pada ketentuan legal formal. Pendidikan pada KAT hendaknya dilakukan tanpa menarik komunitas tersebut tercabut dari budaya lokalnya. Pendidikan formal yang diagung agungkan menjadi bias bagi SAD. SAD tidak bisa memahami konsep pendidikan sebagai sebuah investasi jangka panjang. SAD di Jambi sulit menerima investasi yang demikian panjangnya ( sekolah formal selama 12 tahun dari SD-SMA) dengan hasil yang belum pasti. Sebagai pembanding, lebih baik mereka berinvestasi menanam karet alam selama 8 tahun sudah menghasilkan, Tapi sekolah ? Belum tentu.

\subsection{Pendidikan Alternatif Upaya Meningkatkan Kualitas SDM Suku Anak Dalam}

Pendidikan tidak serta merta hadir dalam kehidupan SAD. Memberikan pendidikan bagi SAD bukanlah hal yang mudah. SAD berkeyakinan apapun yang dihadirkan pada mereka akan mengubah adat dan budaya mereka, atau mengubah Halom (alam) dalam bahasa mereka. Awalnya SAD dihadapkan pada dua situasi yang berat. Pemilihan salah satu dari dua situasi tersebut telah menunjukkan adanya kesadaran yang dipahami oleh SAD. Memilih pendidikan dengan resiko melanggar salah satu adat nenek moyang merupakan proses dialogis untuk memecahkan masalah yang dialami oleh mereka. Sebelum menerima pembelajaran alternatif, mereka harus mendapatkan persetujuan dari rerayo terlebih dahulu agar diijinkan belajar). Pada saat itu rerayo berkumpul untuk mendiskusikan kehadiran pendidikan di tengah-tengah masyarakat Suku Anak Dalam. Adanya ruang dialog antar rerayo menandakan telah muncul kesadaran bersama untuk kepentingan masyarakat SAD. Dialog antar rerayo itu menghasilkan keputusan bahwa pendidikan alternatif boleh dilaksanakan diwilayah mereka.

Pendidikan yang layak dikembangkan bagi SAD bersifat alternatif disesuaikan dengan adat dan budaya mereka. Pola pendidikan seperti ini telah dikembangkan oleh Komunitas Konservasi Indonesia (KKI) Warsi atau sekarang disebut Warsi. Sejak tahun 1997 Warsi sudah aktif mengembangkan pendidikan alternatif dengan metode baca tulis hitung (BTH) untuk komunitas SAD. Guru pertama SAD di Bukit Duabelas bernama Yusak Adrian Hutapea (alm) telah melakukan studi awal untuk pendidikan mereka (Apriansyah, 2015). Metode pendidikan alternatif memiliki kebebasan untuk mengembangkan 
pembelajaran sesuai karakter geografis, ekonomi,sosial dan budaya setempat. Terlalu naï bila pendidikan masyarakat adat tunduk sepenuhnya pada ketentuan legal formal, yang justru menghasilkan generasi yang tercabut dari akar geografis,ekonomi, sosial dan budaya mereka. Sebagai contoh, mereka setiap hari berhadapan dengan berbagai jenis tanaman dan makhluk lain di hutan, makanan yang serba alami dan budaya agraris, tiba tiba diperkenalkan dengan semua produk industri, tanaman industri, budaya kota dan kebiasaan orang kota (Sukrameni, 2015).

Selain Warsi, pendidikan alternatif juga dikembangkan oleh Sokola Rimba. Sokola Rimba terbentuk atas prakarsa Butet Manurung, yang awalnya dulu juga bekerja sebagai fasilitator Warsi, dan pada tanggal 30 September 2003 lahirlah Sokola Rimba (Manurung, 2007) Sokola Rimba di dirikan untuk mendidik anak anak SAD (anak Rimba). Tempat belajar mereka di rumah pelajoron yang ada di dalam Rimba (hutan). Namun jika belum ada rumah pelajoron-nya maka mereka mendirikan susudungon. Anak-anak SAD ( Rimba) yang menjadi murid Sokola Rimba banyak melakukan aktivitas bersama sang guru. Mulai dari pagi hari, mereka akan mencari kayu bakar sebagai bahan bakar untuk memasak. Kemudian bersama-sama mencari bahan makanan yang bisa dikonsumi. Setelah mendapatkan bahan makanan, biasanya mereka akan memasak bersama kemudian makan. Setelah kenyang, barulah mereka belajar bersama sang guru. Untuk jadwal belajar sangat tentatif tergantung keinginan dari murid-murid. Setelah dirasa bosan, murid-murid akan bermain bersama atau kadang akan membantu orang tua mencari louk. Ketika hari menjelang sore atau malam, barulah murid-murid kembali ke rumah pelajoron untuk menyiapkan makan malam bersama sang guru. Seperti sebelumnya, setelah kenyang mereka akan melanjutkan pembelajaran hingga larut malam (Gambar 1 dan 2) 

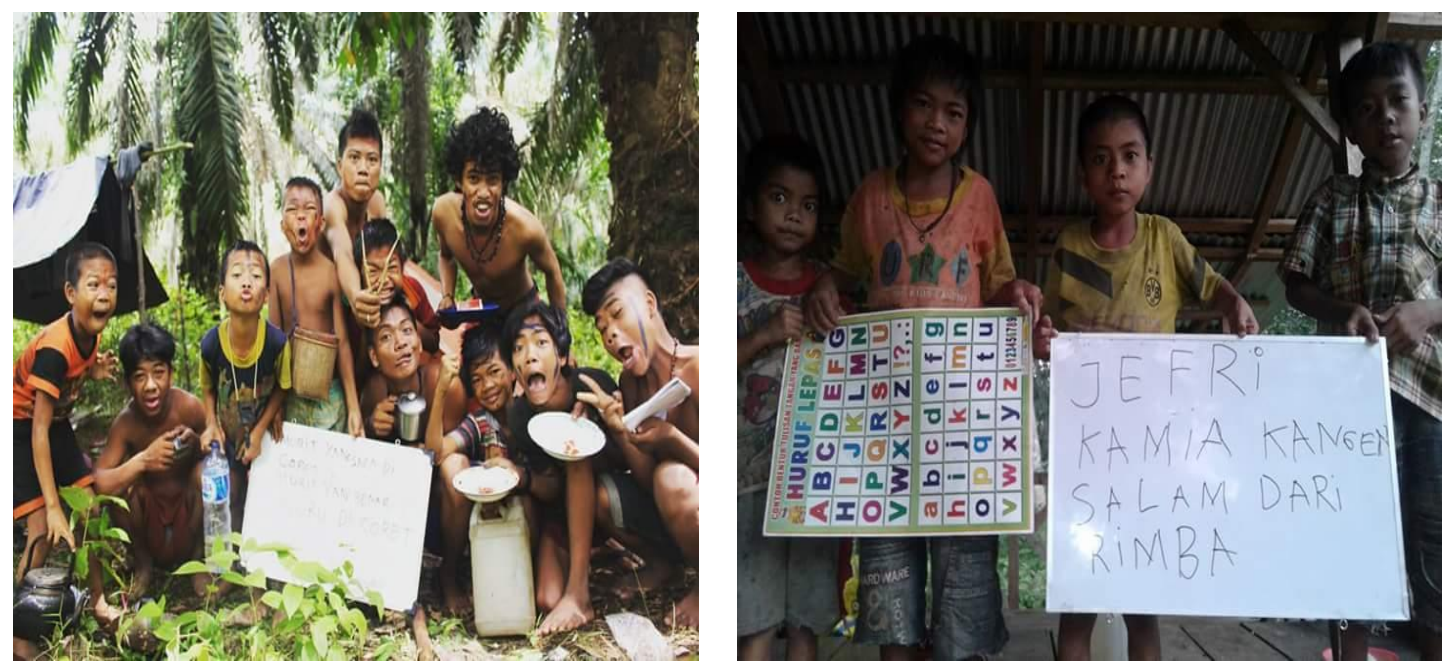

Gambar 1 dan 2 (Anak anak Rimba (SAD) bersama Fasilitator Sokola Rimba (Dokumentasi Sokola Rimba)

Upaya pendidikan alternatif yang lain adalah menghadirkan rumah singgah yang menjadi tempat bersekolah anak anak SAD. Sudah kebiasaaan bagi SAD setiap hari pasar mereka akan berbondong bondong ke pasar terdekat dari pemukiman mereka. Hari pasar merupakan moment yang sangat penting bagi SAD, selain untuk menjual hasil hutan juga dimanfaatkan mereka untuk membeli berbagai barang kebutuhan sehari hari. Pada hari pasar, biasanya para orang tua akan mengajak serta anak anak mereka, dan mereka akan datang sehari sebelum hari pasar. Kesempatan ini dimanfaatkan oleh beberapa fasilitator pendidikan untuk ikut memberikan pendidikan bagi anak-anak SAD. Pada periode 20082015 tercatat ada 451 anak SAD yang mengikuti program baca-tulis-hitung (BTH) yang terdiri atas 451 siswa BTH, 53 siswa SD, 12 siswa SLTP, 4 siswa SLTA dan 1 orang mahasiswa di Perguruan Tinggi ( Muchlis, 2017).

Upaya pendidikan alternatif juga dilakukan oleh Balai Taman Nasional Bukit Duabelas (BTNBD) yang ikut mendirikan sekolah non formal bernama Rimbo Pintar. Fasilitator pendidikan mendatangi anak anak SAD dan memberikan pelajaran pada mereka. Dalam seminggu sebnayak 3 kali mereka mengunjungi anak anak SAD. Selain BTNBD, upaya pendidikan alternatif juga dilakukan oleh pihak perusahaan yang mendiami sekitar hutan, seperti yang dilakukan oleh PT. SAL Sarana Aditya Loka). Melalui program CSR ( corporate social responsibility) PT SAL memberikan pemberdayaan pendiidikan bersifat non formal, selain itu melalui program CSR, Perusahaan juga memberikan makan siang gratis pada anak anak SAD (Gambar 3 dan 4) 

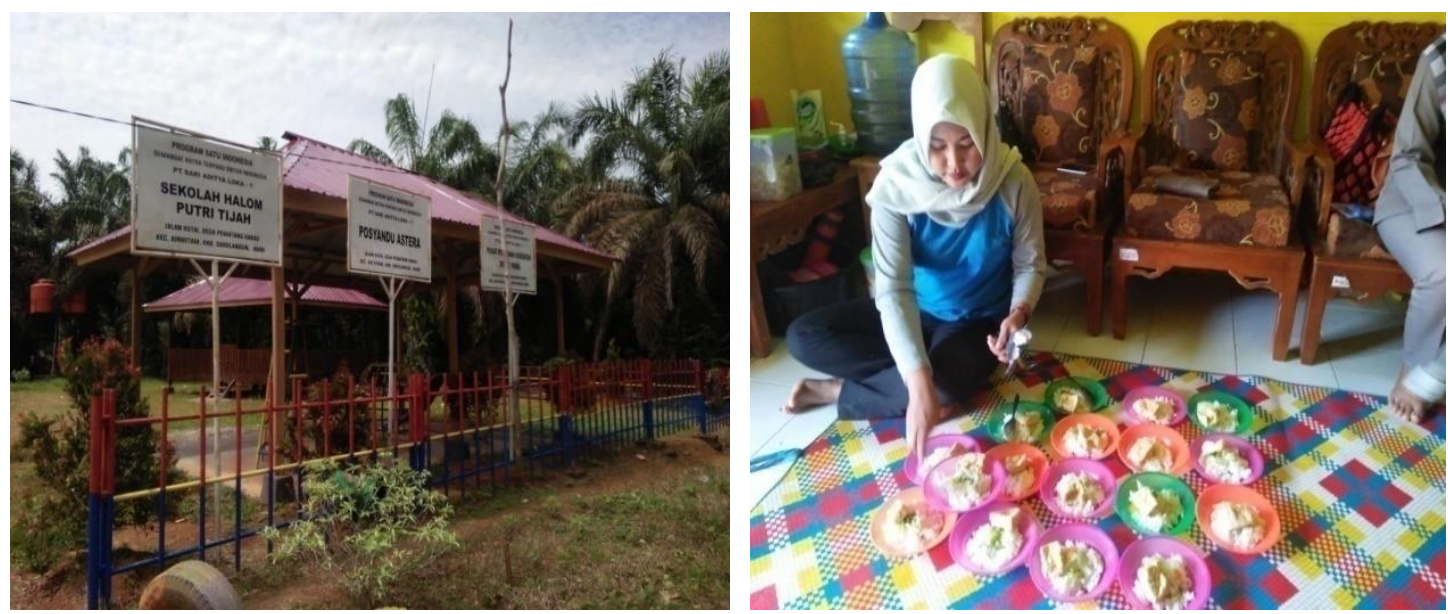

Gambar 3 dan 4 Program CSR (Corporate Social Responsibility) oleh PT SAL untuk memberdayakan anak anak SAD

Setelah lebih dari lima belas tahun proses fasilitasi pendidikan terus dilakukan silih berganti, seiring dengan perkembangannya SAD tidak hanya membutuhkan fasilitasi sebatas baca tulis hitung. Mulai ada upaya mengenalkan anak anak SAD pada pendidikan formal. Upaya memasukkan anak anak SAD kesekolah formal sama sekali bukan hal yang mudah. Perlu usaha keras untuk menyakinkan berbagai pihak hingga sampai pada tahapan tersebut. Butuh proses yang tidak pendek untuk memotivasi anak anak, menyakinkan para orang tua, berkoordinasi dengan pihak sekolah dan instansi terkait. Pendidikan formal terlalu kaya akan muatan tetapi miskin akan konteks lokal. Upaya mendorong pengakuan terhadap pendiidkan alternatif oleh Negara tentunya sudah menjadi sebuah kemutlakkan. Tanpa intervensi Negara akan sulit bagi anak SAD untuk memiliki pengakuan legal formal akan kemampuan akademik mereka. Ketiadaan pengakuan legal formal sama artinya dengan merampas kesempatan mereka berkompetisi memperebutkan peluang-peluang hidup untuk kehidupan yang lebih baik.

\subsection{Pendidikan Formal Tonggak Sejarah Bagi Suku Anak Dalam}

Tonggak sejarah pendidikan bagi SAD mengalami babak baru di tahun 2005, dimana pendidikan formal mulai di rintis. Saat itu kesadaran kritis dari anak anak SAD mulai mucul. Mereka mulai menanyakan : "Macammano caronye akeh mdok jadi lokoter? Akeh ndok jadi lurah." (Bagaimana caranya saya mau jadi dokter? Saya mau jadi lurah?) Cita-cita anak SAD berkaitan dengan apa yang mereka lihat secara langsung dalam kehidupannya (Muchlis, 2017) 
Pern dari Pemerintah Daerah melalui Dinas Pendidikan Kabupaten setempat sangat diharafkan. Salah satu Kabupaten di Propinsi Jambi yang intens dan konsisten membina dan memberdayakan SAD adalah Kabupaten Sarolangun. Pemberdayaan di bidang pendidikan mulai dilakukan oleh Dnas Pendidikan Kabupaten Sarolangun sejak tahun 2008 sampai saat ini. Berbagai jenis bantuan pendidikan telah diberikan pada SAD antara lain : bantuan pakaian sekolah, perlengkapan alat sekolah, makanan gizi tambahan, bahan material olahraga, beasiswa SAD, insentif tambahan untuk guru SAD dan kunjungan pembinaan kelokasi SAD. (Data primer, wawancara dengan Kabid Pendidikan Kab. Saorlangun, 2018).

Untuk melihat kondisi pendidikan SAD di Kecamatan Air Hitam, Kabupaten Sarolangun seperti pada Tabel 1 dibawah ini :

Tabel 1. Kondisi Pendidikan SAD di Kabupaten Sarolangun Pada Tahun 2017

\begin{tabular}{|c|c|c|c|}
\hline \multirow[t]{2}{*}{ No } & Lembaga & Tempat & Jumlah \\
\hline & Pendidikan & & Murid \\
\hline \multirow[t]{8}{*}{1} & PAUD & 1. PAUD Putri Tijah Air Hitam & 34 \\
\hline & & 2. Nurul Islam Air Hitam & 33 \\
\hline & & 3. Nurul Ikhlas Air Hitam & J \\
\hline & & 4. Uslahul Ummah CNG & 27 \\
\hline & & 5. PAUD SAD Punti Kayu I Air Hitam & 25 \\
\hline & & 6. PAUD SAD Punti Kayu II Air Hitam & \\
\hline & & & 30 \\
\hline & & & 20 \\
\hline 2 & Paket & - & - \\
\hline \multirow[t]{7}{*}{3} & SD & 1. SD No 198/VII Sei Pelakar Kec Bathin VIII & 30 \\
\hline & & 2. SD No 89/VII Pl Lintang Kec. Bathin VIII & 21 \\
\hline & & 3. SD YPPL PT Emal Pauh Kec. Pauh & 21 \\
\hline & & 4. SD No 213/VII Sepintun Kec. Pauh & 13 \\
\hline & & 5. SD No 204/VII Tj raden Kec. Limun & 51 \\
\hline & & 6. SD No 34/VII Lubuk Bedorong Kec Limun & \\
\hline & & 7. SD No 191?VII Pematang Kabau, Air Hitam & 35 \\
\hline
\end{tabular}


8. SD No 197/VII Kampung VII Sekar Kec $\mathrm{CNG}$
4 SMP SMP Satu Atap 12 Negeri Sarolangun 5 SLTA SMK Sarolangun

\section{Sumber : Dinas Pendidikan Kabupaten Sarolangun Tahun 2017}

Tabel 1 menunjukkan bahwa Pemerintah (Negara) turut memperhatikan pengembangan dan peningkatan sumber daya manusia, khususnya pengembangan Suku Anak Dalam . Anak-anak SAD diberikan pendidikan secara gratis mulai dari PAUD sampai SLTA. Akan tetapi tetap saja minat pendidikan anak anak SAD untuk mengikuti pendidikan formal masih rendah. Salah satu penyebabnya adalah jauhnya jarak yang ditempuh anak anak SAD untuk belajar ke sekolah formal. Bila ingin belajar kesekolah formal mereka harus menempuh sekitar 6-7 km atau 2 jam perjalanan baru sampai, karena kesekolah formal yang terdekat ada di sekitar pemukiman warga transmigrasi.

\subsection{Perubahan Pendidikan SAD, Simbol Perlawaanan Penindasan}

Pada tahap awal masuknya pendidikan kedalam struktur masyarakat Suku Anak Dalam, pendidikan diharafkan dapat membantu mereka untuk menjaga halom rimba (alam hutan) Dengan pendidikan semoga halom Rimba terjaga. Kehadiran pendidikan di tengahtengah masyarakat SAD juga mengubah struktur yang telah lama dijalankan oleh mereka. Sejalan dengan diperbolehkannya pendidikan masuk kedalam masyarakat SAD membuat mereka memiliki pengaturan baru mengenai pendidikan tersebut. Semua ini dilakukan semata-mata agar terlepas dari penindasan yang selama ini dialami oleh mereka.

Anak anak SAD kini mulai mengakses bahan bacaan seperti koran, buku, majalah dll. Anak-anak tersebut juga mulai memahami bacaan-bacaan yang berkaitan dengan bagaimana Suku Anak Dalam dipahami oleh orang luar. Mereka mulai memahami bahwa dengan bisa membaca, menulis dan berhitung maka mereka akan mengerti lebih banyak lagi. Keadaan tersebut membawa pemahaman akan posisi mereka di dalam struktur masyarakat secara umum dan diharapkan dengan pendidikan mereka juga dapat menjaga lingkungan hutannya untuk menjamin keberlanjutan kehidupan mereka di masa depan. 


\section{KESIMPULAN}

Pendidikan bagi kelompok suku minoritas di Indonesia, khususnya masyarakat Suku Anak Dalam sangat penting dilakukan. Model pendidikan yang berbasis adat dan budaya setempat adalah kunci keberhasilannya. Pengembangan model pendidikan alternatif berbasis budaya dan kearifan lokal setempat merupakan model pendidikan yang paling tepat diterapkan untuk membina Komunitas Adat Terpencil (KAT). Integrasi dan kerjasama semua aktor pemberdaya baik Pemerintah, Swasta dan NGO adalah faktor utama pendukung keberhasilan pemberdayaan ini.

\section{DAFTAR PUSTAKA}

Apriansyah, Huzer. Masa depan Pendidikan Orang Rimba sebuah Refleksi. Alam Sumatera, Eisi Oktober 2014.KKI -Warsi

Prasetijo, Adi. 2011. Serah Jajah dan Perlawanan Yang Tersisa. Etnografi Orang Rimba di jambi. Wedatama Widya Sastra. Jakarta

Muchlis Fuad, 2017. Praktik Komunikasi dalam pemberdayaan Orang Rimba di Taman Nasional Bukit Duabelas Provinsi Jambi. Disertasi. Sekolah Pascasarjana.IPB. Bogor Manurung, Butet.2007. Sokola Rimba ( Pengalaman Belajar Bersama Orang Rimba).Insist Press Yogyakarta

Manan, 2018. Pendidikan dan Perubahan Sosial : Studi di Kalangan Suku Anak Dalam Mengenyam Pendidikan. Skripsi S1 Fisipol. UGM

Rokhdian D. 2012. Alim Rajo Disembah, Piado Alim Rajo Disangah: Ragam Bentuk Perlawanan Orang Rimba Makekal Hulu Terhadap Kebijakan Zonasi Taman Nasional Bukit Dua Belas. Jambi. Program Pascasarjana, Fakultas Ilmu Sosial dan Ilmu Politik. Universitas Indonesia. Jakarta.

Seymou Smith Charlotte.1986. Maximillan Dictionary of Anthropology. Landon. Macmillan Press.

Suparlan, Parsudi,.2004 Hubungan Antar Suku Bangsa. Jakarta. YPKIK Apriansyah, Huzer. Masa depan Pendidikan Orang Rimba sebuah Refleksi. Alam Sumatera, Eisi Oktober 2014.KKI -Warsi

Sukrameni \& Hermayulis. Mewujudkan Kemerdekaan Pendidikan Bagi Komunitas Adat, Eisi Oktober 2014.KKI -Warsi 